\title{
An Improved Model Predictive Control Method to Drive an Induction Motor Fed by Three-Level Diode-Clamped Indirect Matrix Converter
}

\author{
Arman Farhadi $^{1, *}$, Amir Akbari $^{1}$, Ali Zakerian ${ }^{2}$, Mohammad Tavakoli Bina ${ }^{1}$ \\ ${ }^{1}$ Department of Electrical and Computer Engineering, K. N. Toosi University of Technology, Tehran, Iran \\ ${ }^{2}$ Department of Electrical and Computer Engineering, Mississippi State University, Mississippi, USA \\ Received 05 June 2020; received in revised form 17 August 2020; accepted 14 September 2020 \\ DOI: https://doi.org/10.46604/ijeti.2020.5870
}

\begin{abstract}
In this paper, an improved model predictive control method is proposed to drive an induction motor fed by a three-level matrix converter. The main objective of this paper is to present a novel method to increase the switching frequency at a constant sampling time. Also, it is analytically discussed that increasing the switching frequency not only can decrease the motor current ripples, but it can also significantly reduce its torque ripples. Finally, this study demonstrates that reducing the motor current ripple will improve the quality of the supply current. To be the accurate model and validate the motor drive system, a co-simulation method, which is a combination of FLUX and MATLAB software packages, is employed to find the simulation results. The findings indicate that the proposed method diminishes the THD of the supply current up to $26 \%$ approximately. Furthermore, increasing the switching frequency results in the torque ripple reduction by up to $10 \%$ almost.
\end{abstract}

Keywords: model predictive control, three-level matrix converter, induction motor, switching frequency, torque ripple

\section{Introduction}

Lack of dc-link capacitors makes the matrix converter a suitable choice for lightweight and low volume applications. Besides, matrix converters have other characteristics such as input and output sinusoidal currents, and the unity power factor in the each load and regeneration capacity [1]. In recent years, researchers have shown an increasing interest in matrix converters used in applications such as variable speed drives [2-3], flexible alternating current transmissions [4], and renewable energy conversion systems [5-7].

Matrix converters in high-power drives have certain constraints such as high currents and voltages on power switches. The hybrid structure of power converters may yield noticeable advantages that can address these problems [8-10]. An effective idea to augment the converter power capacity is the combination of matrix and three-level converters. Hence, to make a three-level matrix converter, the three-level diode-clamped indirect matrix converter (TLDCIMC) topology is a very appropriate candidate. The TLDCIMC has two main input sections: cascaded-rectifier and diode-clamped inverter. The input cascaded-rectifier provides two dc-links for the diode-clamped inverter that makes a three-level output voltage. This structure is suitable for high-voltage and high-power applications due to the reduction in the output harmonic distortion, common-voltage mode, stress voltage on the switches, and variation rate dv/dt [11]. But, its complex model may lead to some difficulties for the modulation and the design of the control system.

* Corresponding author. E-mail address: farhadi@email.kntu.ac.ir 
On the other hand, finite control set model predictive control (FCS-MPC) has gained in popularity among many researchers [12-17]. This method is applicable in different types of linear and non-linear systems and has some advantages such as high-speed response and controlling multiple variables without creating extra loops. In this method, the control variables are measured in the first step and then the predictive model predicts their values for the next sampling time. Next, a cost function is defined for the system. Afterward, the controller evaluates the switching states and selects the best one to minimize the cost function and apply it to the converter [18-19].

An effective way to improve the quality of the converter current is by increasing the switching frequency. As a result, it reduces the torque ripple of the motor [20-21]. In conventional methods, a modulator receives the reference signal to perform the switching with a constant frequency [22]. Besides, the switching frequency can be increased by reducing the controller sampling time. This action reduces the prediction time for selecting an optimal switching state [23]. Therefore, the switching states will change in a shorter period, and subsequently, the switching frequency will increase. Hence, the processor may encounter some problems owing to many calculations at each sampling time.

The FCS-MPC has no modulator and the switching frequency is not precisely determined by the controller designer. In this method, a cost function is defined for the converter to determine the optimal switching state at each sampling time. This paper presents a new method to increase the number of commutations at each sampling time to raise the switching frequency as well as reduce the motor current ripple. Thus, not only can this method decrease the torque ripple without reducing the sampling time, but it can also diminish the total harmonic distortion (THD) of the source current.

Increasing the switching frequency could be considered an indispensable constraint for a power converter since a high switching frequency leads to high power losses. Thereby, the efficiency of the converter would ultimately decrease [24]. Yet, the proposed method demonstrates that increasing the switching frequency would not lead to a significant decrease in the efficiency of the converter.

In this study, the FCS-MPC method is used to drive an induction motor by a TLDCIMC. A cost function is also defined to control the stator currents. Increasing the switching frequency is the other purpose of the cost function to reduce the motor torque ripple as well as the THD of the supply current. As the motor behavior becomes more nonlinear due to the variable conditions of the drive, the effects of the magnetic saturation on the control algorithms should be taken into account. FEA that is the most precise modelling tool for the numerical analysis of electrical machines is used to simulate the motor by FLUX software. The simulation of the induction motor drives in MATLAB/Simulink and provides a suitable environment for the design of the controller due to various mathematical tools. By coupling these two software packages, the co-simulation results of the proposed drive and the presented method for increasing the switching frequency are drawn with a high level of accuracy.

This paper is organized as follows. The power circuit of the three-level diode-clamped indirect matrix converter is described in Section 2. Section 3 presents a detailed description of the proposed predictive controller. Section 4 describes the effect of using the proposed method on the induction motor torque ripple and the THD of the supply current. In Section 5, the proposed co-simulation method is defined and Section 6 indicates extensive simulation results compared to the conventional ones. Finally, the c is included in Section 7.

\section{Converter Modeling}

Fig. 1 shows the structure of the TLDCIMC which is made from a cascaded-rectifier, input LC filter, three-coil three-phase transformer, and diode-clamped inverter. There is a connection between the two sections of the cascaded-rectifier and diode-clamped inverter. The cascaded-rectifier structure consists of two series rectifiers. Each rectifier includes six bidirectional switches that are fed from the secondary side of the three-phase transformer. The diode-clamped inverter provides three terminals $\mathrm{P}, \mathrm{Z}$, and $\mathrm{N}$ for the positive electrode, neutral point, and negative electrode of the dc-link, respectively. 
Therefore, the inverter has two DC voltages between " $\mathrm{P}$ " and " $\mathrm{Z}$ " points as well as between " $N$ " and " $\mathrm{Z}$ " points in the inverter's input. The input passive filter including primary-side inductors, secondary and third-side capacitors of the transformer is used to eliminate high-frequency harmonics.

All available rectifier switches $\left(S_{r n h}, \mathrm{~h}=1 \cdots 6\right)$ in the third side are switched similar to the secondary-side rectifier switches $\left(S_{r p h}, \mathrm{~h}=1 \cdots 6 h\right)$. Therefore, the resulted two voltages based on the input voltages and cascaded-rectifier switches are obtained as:

$$
\begin{aligned}
& V_{p}=\left[\begin{array}{lll}
S_{r p 1}-S_{r p 4} & S_{r p 3}-S_{r p 6} & S_{r p 5}-S_{r p 2}
\end{array}\right]\left[\begin{array}{l}
v_{A 1} \\
v_{B 1} \\
v_{C 1}
\end{array}\right] \\
& V_{n}=\left[\begin{array}{lll}
S_{m 1}-S_{m 4} & S_{m 3}-S_{m 6} & S_{m 5}-S_{m 2}
\end{array}\right]\left[\begin{array}{l}
v_{A 2} \\
v_{B 2} \\
v_{C 2}
\end{array}\right]
\end{aligned}
$$

The secondary and the third-side currents of the three-phase transformer are specified by a matrix of the rectifier switches as follows:

$$
\left[\begin{array}{l}
i_{A 1} \\
i_{B 1} \\
i_{C 1}
\end{array}\right]=\left[\begin{array}{l}
S_{r p 1} \\
S_{r p 3} \\
S_{r p 5}
\end{array}\right] I_{P}-\left[\begin{array}{l}
S_{r p 4} \\
S_{r p 6} \\
S_{r p 2}
\end{array}\right] \frac{I_{z}}{2}
$$

where $I_{p}, I_{n}$, and $I_{z}$ are positive and negative dc-links, and null wire currents, respectively.

At least one of the $S_{r p 1}, S_{r p 3}$, and $S_{r p 5}$ switches and one of the $S_{r p 4}, S_{r p 6}$, and $S_{r p 2}$ switches must be on so that the current path does not be disconnected toward the output load. Thus, there are 9 correct switching states for the cascaded-rectifier. The switching states are decreased to 6 by considering that two switches in each rectifier phase should not be on simultaneously. Table A.1 and Table A.2 in the Appendix depict the correct switching states as well as the generated voltages by the upper and the lower rectifiers shown in Fig. 1.

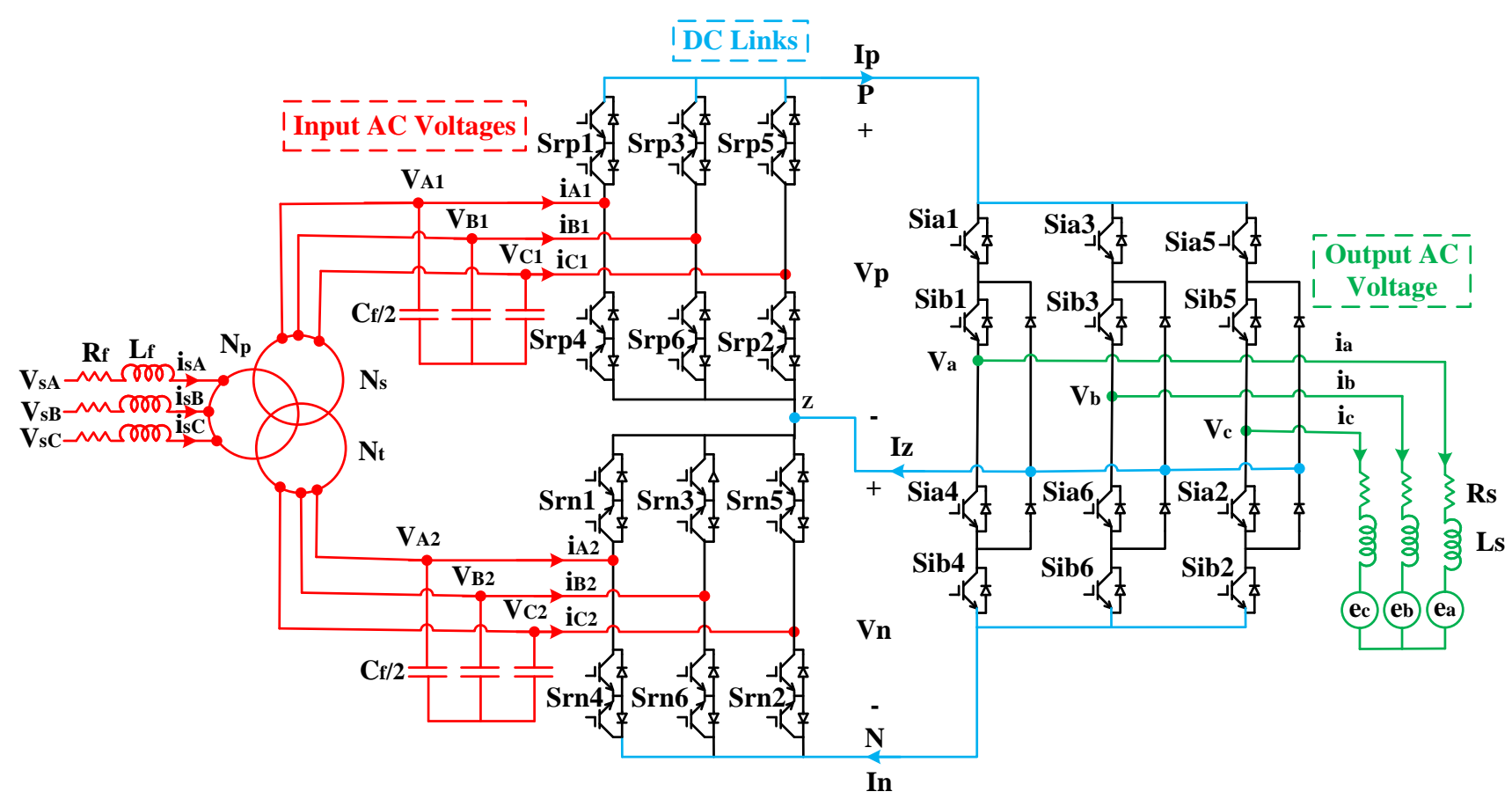

Fig. 1 Power circuit of three-level diode-clamped indirect matrix converter 
If $N_{p}, N_{s}$, and $N_{t}$ are assumed as the turn number of primary, secondary, and third windings of the transformer, the source currents are obtained by:

$$
\left[\begin{array}{l}
i_{s A} \\
i_{s B} \\
i_{s C}
\end{array}\right]=\left[\begin{array}{l}
\frac{N_{s}}{N_{p}} i_{A 1}+\frac{N_{t}}{N_{p}} i_{A 2} \\
\frac{N_{s}}{N_{p}} i_{B 1}+\frac{N_{t}}{N_{p}} i_{B 2} \\
\frac{N_{s}}{N_{p}} i_{C 1}+\frac{N_{t}}{N_{p}} i_{C 2}
\end{array}\right]
$$

Two dc-link currents $\left(I_{p}, I_{n}\right)$ and null wire current $\left(I_{z}\right)$ can be calculated by a matrix of inverter switches and load currents as follow:

$$
\left[\begin{array}{l}
I_{p} \\
I_{n} \\
I_{z}
\end{array}\right]=\left[\begin{array}{ccc}
S_{i a 1} & S_{i a 3} & S_{i a 5} \\
-S_{i b 4} & -S_{i b 6} & -S_{i b 2} \\
S_{i a 1}-S_{i b 1} & S_{i a 3}-S_{i b 3} & S_{i a 5}-S_{i b 5}
\end{array}\right]\left[\begin{array}{l}
i_{a} \\
i_{b} \\
i_{c}
\end{array}\right]
$$

Finally, the output voltages are calculated by a matrix of diode-clamped inverter switches and dc-link voltages $\left(V_{p}\right.$ and $\left.V_{n}\right)$ as follows:

$$
\left[\begin{array}{l}
v_{a z} \\
v_{b z} \\
v_{c z}
\end{array}\right]=\left[\begin{array}{ll}
S_{i a 1} & -S_{i b 4} \\
S_{i a 3} & -S_{i b 6} \\
S_{i a 5} & -S_{i b 2}
\end{array}\right]\left[\begin{array}{c}
V_{p} \\
V_{n}
\end{array}\right]
$$

Since the output load must not be open circuit, there are 27 switching states for a diode-clamped inverter [25]. Therefore, the controller has to consider $6 \times 27=162$ possible switching states as shown in Table A.3 in the Appendix.

The output load of the TLDCIM is an induction motor with the following mathematical model [26]:

$$
v_{o}=L_{s} \frac{d i_{o}}{d t}+R_{s} i_{o}+e
$$

where $R_{s}, L_{s}$, and $e$ are stator resistance, stator inductance and the back electromotive force (EMF) of the motor, respectively. $v_{o}$ is the vector of the output voltages $\left(v_{a z}, v_{b z}, v_{c z}\right)$ and $i_{o}$ is the vector of the load currents $\left(i_{a}, i_{b}, i_{c}\right)$.

\section{Predictive Controller Scheme}

Fig. 2 describes the proposed algorithm of the FCS-MPC method. In the first step, the measurement of the stator currents was performed at sampling time $(\mathrm{k})$. Using the predictive model, the behavior of the currents in the next sampling time $(\mathrm{k}+1)$ was predicted for all 162 switching states. In the next step, a cost function was defined for the system. The main constraint for the cost function was calculating the error between the predicted currents and their reference values in sampling time $(\mathrm{k}+1)$.

The constraint of increasing the number of converter commutations can also be added to the cost function as an additional term. In this constraint, the available switching states were compared to the switching states maintained since previous sampling time (k-1). The cost function evaluates all correct switching states in each sampling time. Finally, the switching state with the least error was selected to be applied to the converter in the next sampling time. 


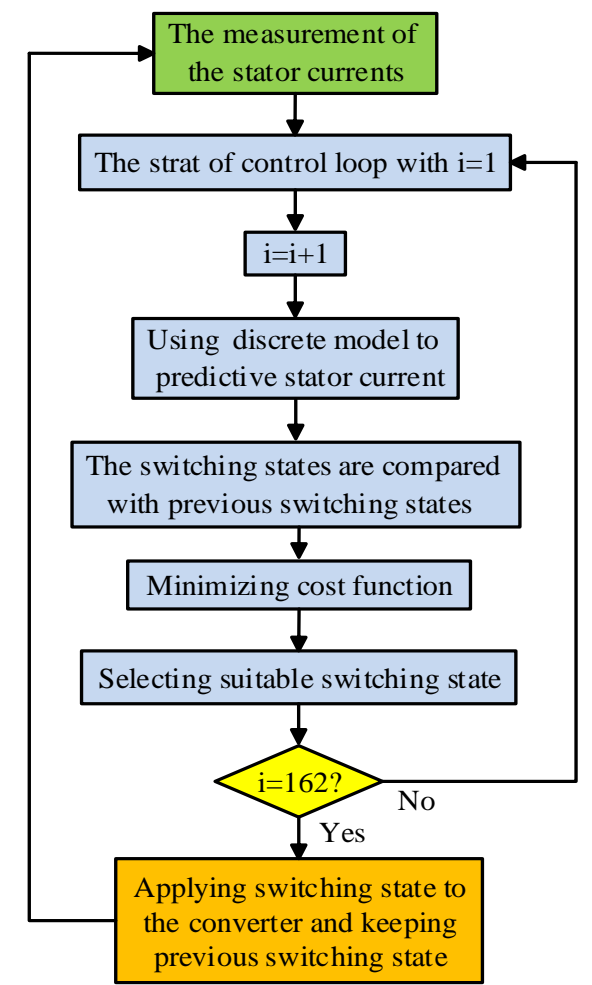

Fig. 2 The algorithm of the FCS-MPC method

\subsection{System predictive model}

Primarily, to obtain the stator current predictive model, the stator current derivative is written by Euler approximation in the discrete equation:

$$
\frac{d i_{o}}{d t}=\frac{i_{o}(k+1)-i_{o}(k)}{T_{s}}
$$

where $T_{S}$ is the sampling time. Then by substituting the above equation in the load current dynamically described in Eq. (8), the predictive term of the load current in time $k+1$ is obtained. Due to the measured values of load current $i_{o}(k)$ and output voltages $v_{o}(k)$ obtained from all switching states, the predicted value of stator current is found by:

$$
i_{o}(k+1)=\left(1-\frac{R_{s} T_{s}}{L_{s}}\right) i_{o}(k)+\frac{T_{s}}{L_{s}}\left(v_{o}(k)-e(k)\right)
$$

The back EMF of the motor which is shown in Eq. (10) can be estimated by calculating currents and voltages:

$$
e(k-1)=v_{o}(k-1)-\frac{L_{s}}{T_{s}} i_{o}(k)-\left(R_{s}-\frac{L_{s}}{T_{s}}\right) i_{o}(k-1)
$$

Since the sampling frequency is more than the frequency of back EMF, there is not a significant change in the back EMF of each sampling time. As a result, it can be assumed that $e(k-1)$ is approximately $e(k)$.

\subsection{Cost function}

The main purpose of the cost function, considering 11-norm [27], is defined on the alpha-beta coordinate system that calculates errors between the source and predicted currents as follow:

$$
g=\Delta i_{o}=\left|i_{o \alpha}^{*}(k+1)-i_{o \alpha}(k+1)\right|+\left|i_{o \beta}^{*}(k+1)-i_{o \beta}(k+1)\right|
$$


where $i_{o \alpha}(k+1)$ and $i_{o \beta}(k+1)$ are real and imaginary parts of the predicted stator current in the alpha-beta form. Moreover, $i_{o \alpha}^{*}(k+1)$ and $i_{o \beta}^{*}(k+1)$ are real and imaginary parts of the reference current. To increase the number of commutations of TLDCIMC switches in the sampling time $\mathrm{k}$, it is proposed that the number of switching state changes in all switches of cascaded-rectifier and diode-clamped inverter is also added to obtain:

$$
\Delta S=\sum_{h=1}^{6}\left|S_{r p h}(k)-S_{r p h}(k-1)\right|+\left|S_{r n h}(k)-S_{r n h}(k-1)\right|+\sum_{y=1}^{6}\left|S_{i a y}(k)-S_{i a y}(k-1)\right|+\left|S_{i b y}(k)-S_{i b y}(k-1)\right|
$$

where $A$ is a constant value. If the number of commutations in each voltage source cycle must be evaluated by calculating its average for all TLDCIMC switches, the average switching frequency in each cycle can be attained using the following equation:

$$
f_{s w}=\frac{N f_{s}}{\Delta S}
$$

where $f_{S}$ and $N$ are the frequency of the voltage source and the number of converter switches, respectively. Finally, the system cost function is proposed by two terms:

$$
g=\Delta i_{o}+\frac{A}{\Delta S}
$$

The term $\Delta S$ in each switching state causes cost changes in the cost function which can lead to select an optimum state with a more commutation number in the FCS-MPC method. As $A$ increases, a rise in the commutation numbers of the cost function becomes more important. Consequently, it leads to an increase in the switching frequency.

\section{Reducing Motor Torque Ripple and Supply Current THD}

According to Eqs. (1), (2), and (7), the output voltage of the converter is derived as:

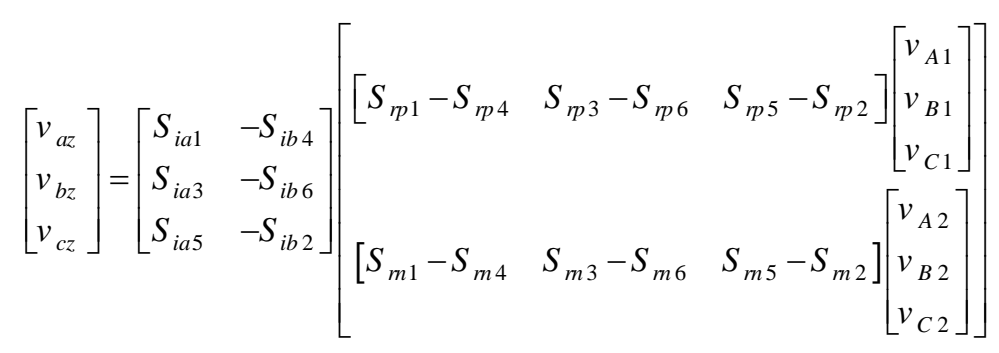

The output voltage includes pulses in which their amplitude is determined by the transformer voltages. Their frequency is obtained by the matrix of the converter switching states. By changing the switching states with a higher frequency, the frequencies of the output voltage harmonics will be increased. As a result, the output voltage harmonics of the converter will remain at higher frequencies in comparison to the main component of the output voltages. The Fourier series of the output voltages is presented as:

$$
v_{o}=V_{o 1} \cos \left(\omega_{o 1} t+\varphi\right)+\sum_{n=2,3, \ldots} V_{o n} \cos \left(n\left(\omega_{o 1} t+\varphi\right)\right)
$$

where $V_{o 1}$ and $V_{o n}$ are the amplitudes of the fundamental component and the harmonics of the output voltage. $\omega_{i o 1}$ is the fundamental frequency and $\varphi$ is $0, \pm 2 \pi / 3$. Thus, the motor current equation based on the output voltage can be written as:

$$
i_{o}=\frac{v_{o}-e}{Z_{s}}=\frac{V_{o 1}}{\sqrt{R_{s}^{2}+\left(\omega_{o 1} L_{s}\right)^{2}}} \cos \left(\omega_{o 1} t-\theta+\varphi\right)+\sum_{n=2,3, \ldots} \frac{V_{o n}}{\sqrt{R_{s}^{2}+\left(n \omega_{o 1} L_{s}\right)^{2}}} \cos \left(n\left(\omega_{o 1} t-\theta+\varphi\right)\right)-\frac{e}{Z_{s}}
$$


where $\theta$ represents the phase difference between the stator voltage and the stator current, and $Z_{s}$ is the motor impedance. It can be seen from Eq. (18) that the larger the amplitude of the $\mathrm{n}^{\text {th }}$ component of the converter output voltage harmonics, the smaller harmonics of the motor current. As a result, the switching frequency component is further away from the main component frequency, and thus, the ripple of the motor current reduces. On the other hand, the motor torque can be calculated using the following Eq. (18) [28]:

$$
T_{e}=\frac{3}{2} p \operatorname{Im}\left\{\bar{\psi}_{s} i_{o}\right\}
$$

where $\Psi_{s}$ and $p$ represent the stator flux and the number of poles, respectively. It can be deduced from Eq. (19) that by reducing the ripple of the motor current. Additionally, the ripple of the motor torque will be also decreased.

According to Eqs. (3)-(6), the relation between the input and the output rectifier currents can be derived as:

$$
i_{i}=M_{S r i} \times i_{o}
$$

Where $i_{i}\left(i_{A 1,2}, i_{B 1,2}, i_{C 1,2}\right)$ is the input rectifier current, and $M_{S r, i}$ is a matrix of the converter switching states. Therefore, with the same argument as stated for the output voltage of the converter, the higher frequency of the switching state changes will result in the higher frequency of the input current harmonics. Accordingly, the switching frequency component is further away from the resonance frequency of the input LC filter in a way that the input LC filter resonance can be decreased. Besides, reducing the motor current ripple can reduce the ripple as well as the THD of the converter input current.

\section{Co-Simulation of Flux and MATLAB/Simulink}

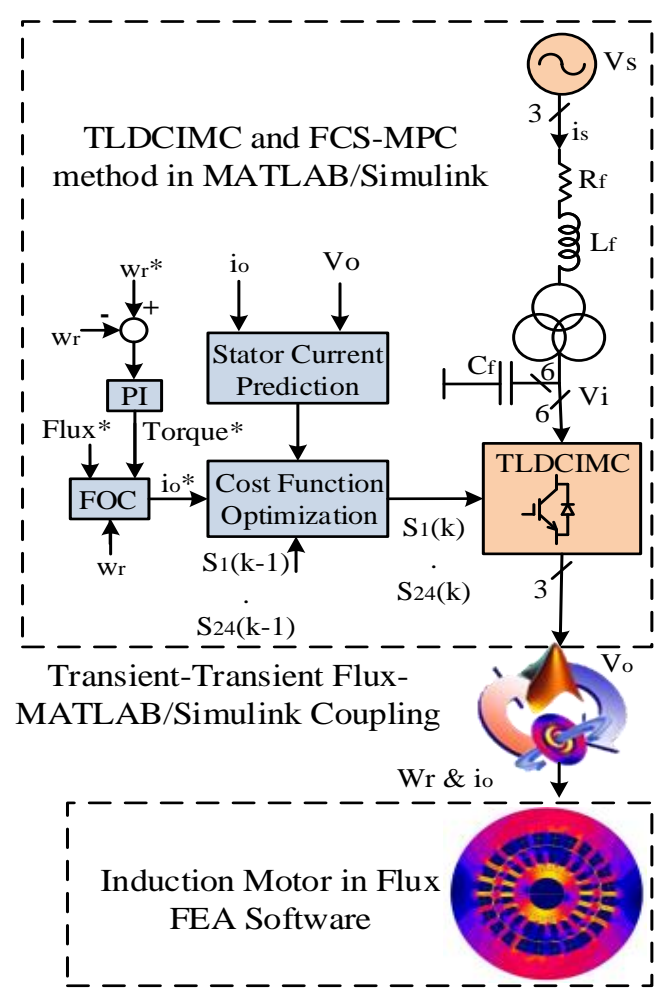

Fig. 3 Block diagram of the transient-transient link between the control method for

TLDCIMC in MATLAB/Simulink and finite element induction motor model

Considering the control algorithm of Fig. 2, the block diagram of the proposed FCS-MPC method for the drive of an induction motor fed by TLDCIMC is shown in Fig. 3. In this method, the current reference of the stator was calculated using field-oriented control (FOC) with the torque reference obtained from the speed controller output. For the precise control, the accurate model which is similar to a practical motor must be considered. Thus, the geometry, mesh, and physics of the 
induction motor were modeled in Flux 2-D FEA software that resulted in getting a very close behavior to the motor. Moreover, the circuits of the control system were modeled in MATLAB/Simulink. Subsequently, a co-simulation was used in the coupling between Flux and MATLAB/Simulink, and the input (voltages) and output (currents and speed) parameters were defined in the transient-transient coupling. Therefore, a high-fidelity coupling of power electronics components and a complicated model of the motor was performed by the co-simulation capability [29].

\section{Results}

In this section, a comparison is made between the FCS-MPC method responses for an induction motor fed by TLDCIMC using conventional and proposed methods. The parameters of the converter, controller, and motor are shown in Table 1. In the conventional method, the cost function (12) was used and the controller's goal is only to control the motor stator current. In the proposed method, the cost function (15) was considered to increase the switching frequency. The sampling frequency for both conventional and proposed methods is assumed to be $20 \mathrm{kHz}$.

Table 1 Converter, controller, and motor parameters

\begin{tabular}{|c|c|c|}
\hline Variable & Description & Value \\
\hline$T_{s}$ & Sampling time & $50 \mu \mathrm{s}$ \\
\hline$A$ & Weighting factor & 8.5 \\
\hline$v_{s}$ & $271 \mathrm{Vrms}$ & Source phase voltage \\
\hline$f_{s}$ & $50 \mathrm{~Hz}$ & Source frequency \\
\hline$N_{S} / N_{P}, N_{T} / N_{P}$ & 1 & Transformer ratio \\
\hline$R_{f}$ & $0.5 \Omega$ & Input filter resistance \\
\hline$L_{f}$ & $1 \mathrm{mH}$ & Input filter inductance \\
\hline$C_{f}$ & $1.5 \mu \mathrm{F}$ & Input filter capacitance \\
\hline$P_{n}$ & $7.5 \mathrm{~kW}$ & Nominal power \\
\hline$V_{n}$ & $658 \mathrm{Vrms}$ & Nominal Line voltage \\
\hline$f_{n}$ & $50 \mathrm{~Hz}$ & Nominal frequency \\
\hline$p$ & 1 & Pole pairs \\
\hline$J$ & $0.0343 \mathrm{~kg} . \mathrm{m}^{2}$ & The moment of inertia \\
\hline$R_{s}$ & $1.54 \Omega$ & Stator resistance \\
\hline$L_{l s}$ & $10.31 \mathrm{mH}$ & Stator leakage inductance \\
\hline$L_{l r}^{\prime}$ & $24 \mathrm{mH}$ & Stator leakage inductance \\
\hline$R_{r}^{\prime}$ & $2.836 \Omega$ & Stator resistance \\
\hline$L_{m}$ & $326 \mathrm{mH}$ & Magnetizing inductance \\
\hline & &
\end{tabular}

Fig. 4 shows the torque and speed results of the system for the conventional and proposed methods. It should be pointed out that if the motor load has a small constant torque, the motor speed may change from -1500 to +1500 rpm. However, as a load with a large constant torque was applied to the motor and simultaneously the motor speed changed from -1500 to +1500 $\mathrm{rpm}$, the motor torque exceeds its nominal value, and the system would become unstable. Thus, the simulation scenario here was that the speed reference changes from $+1500 \mathrm{rpm}$ to $-500 \mathrm{rpm}$ at $\mathrm{t}=0.55 \mathrm{~s}$. Then, the load torque of $19.5 \mathrm{~N}$.m was applied to the motor at $\mathrm{t}=0.4 \mathrm{~s}$. As a result, the motor drive followed the speed reference as well as the dynamic response of the motor drive. Thereby, it is suitable for both methods.

Fig. 5 demonstrates the average switching frequency of the converter for both methods. The switching frequency varied from 1600 to $2200 \mathrm{~Hz}$ and from 3000 to $3600 \mathrm{~Hz}$ for the conventional and proposed methods, respectively. Therefore, because of the increase in the number of commutations at each sampling time, the proposed method has a higher switching frequency than the conventional method. 

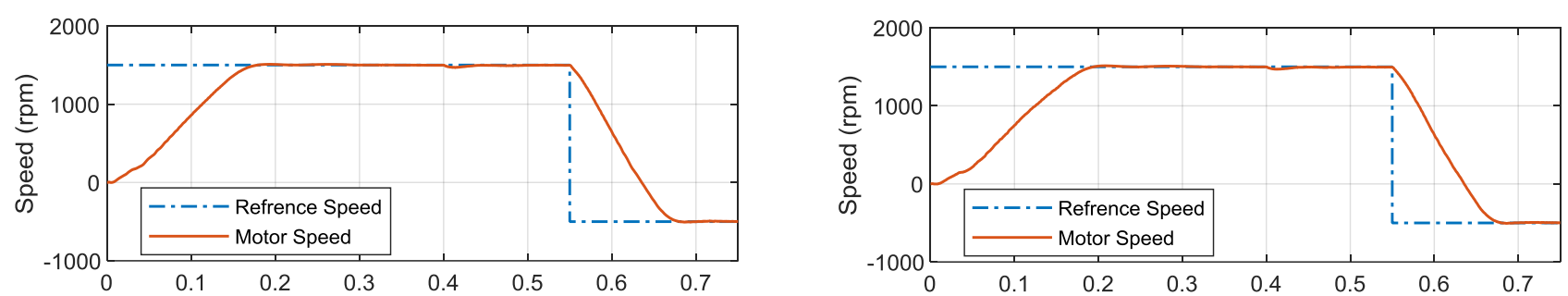

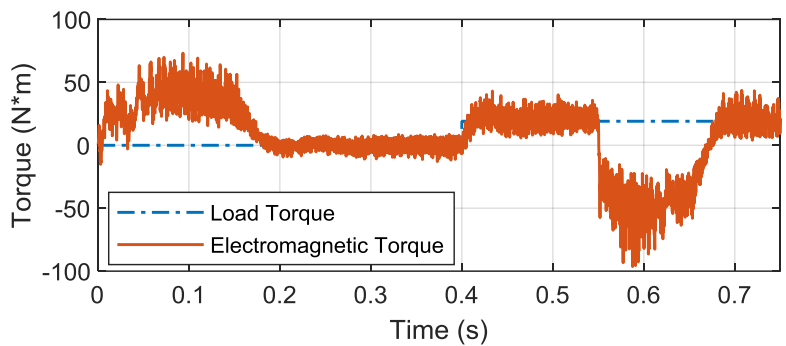

(a) Conventional method

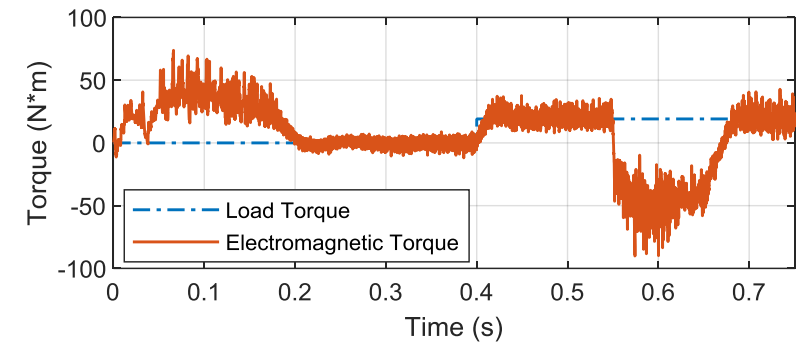

(b) Proposed method

Fig. 4 The speed and torque of the motor for the conventional and proposed methods

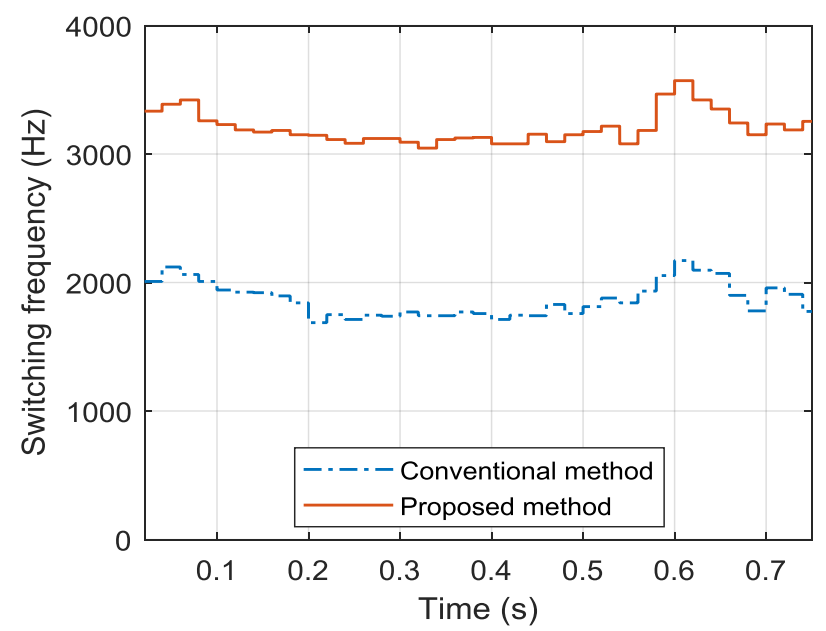

Fig. 5 The average switching frequency for the conventional method and the proposed method

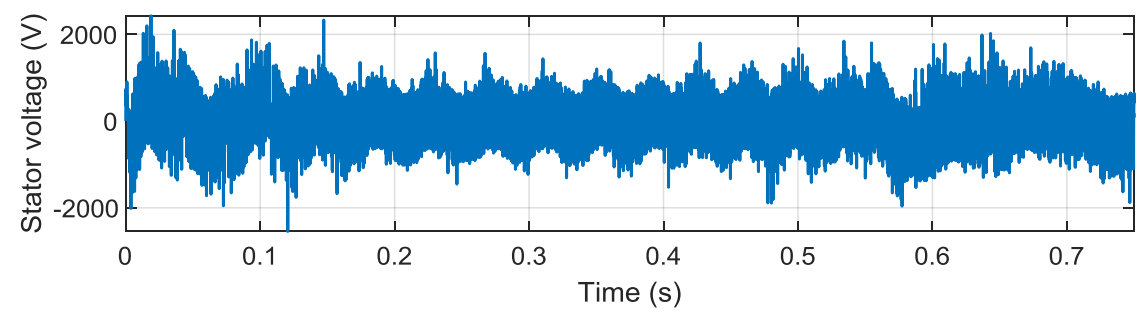

(a) Conventional method

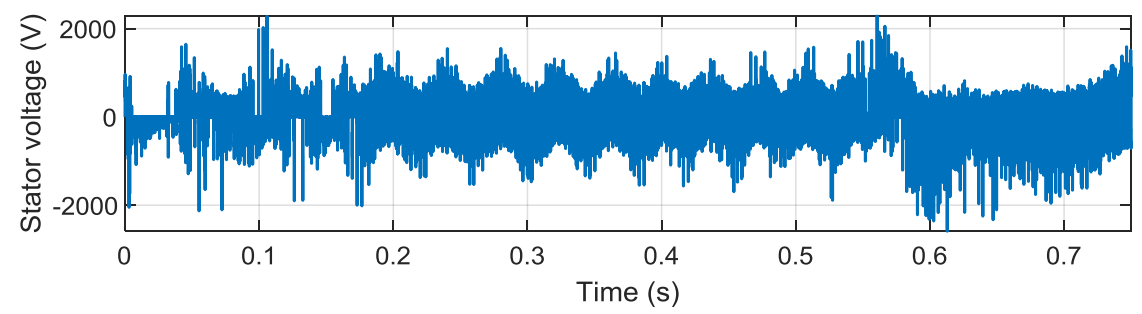

(b) Proposed method

Fig. 6 The stator voltage for the conventional method and proposed methods

Fig. 6 depicts the stator voltage for both conventional and proposed methods and Fig. 7 shows the harmonic spectrum of the stator voltage after applying the load at the steady-state. As can be seen, the amplitude of the voltage harmonics of the conventional method at frequencies lower than $4 \mathrm{kHz}$ is higher than that of the proposed method. Nevertheless, the amplitude 
of the voltage harmonics of the proposed method at frequencies above $4 \mathrm{kHz}$ is higher than that of the conventional method. The THD values of the stator voltage for the conventional and proposed methods are $283.57 \%$ and $263.92 \%$, respectively. Therefore, increasing the switching frequency of the proposed method reduces the harmonic distortion of the output voltage.

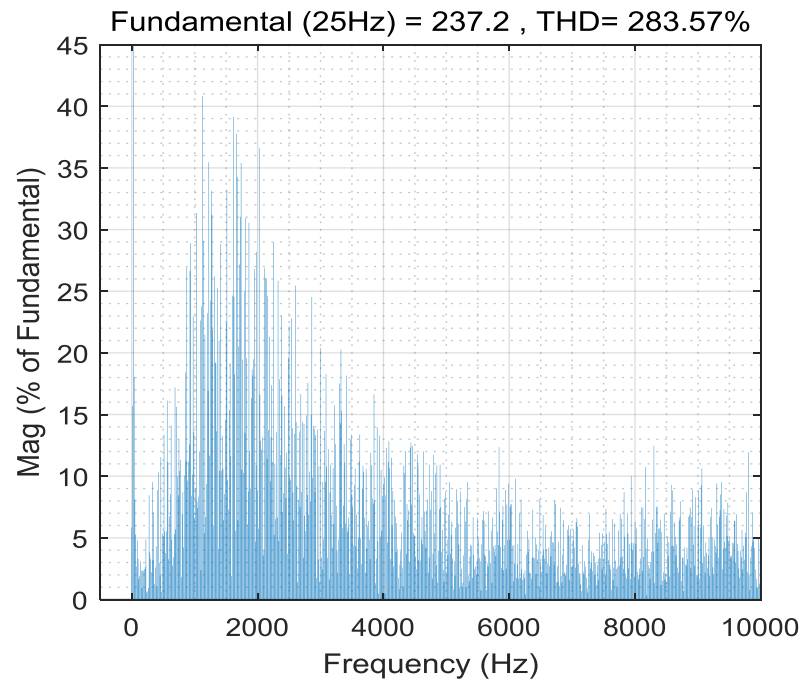

(a) Conventional method

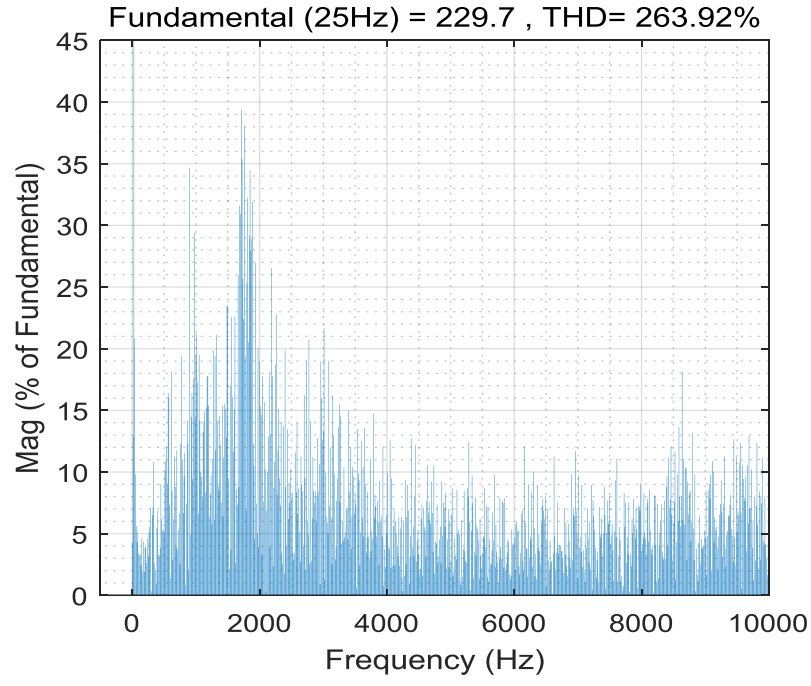

(b) Proposed method

Fig. 7 The harmonic spectrum of stator voltage for the conventional and proposed methods

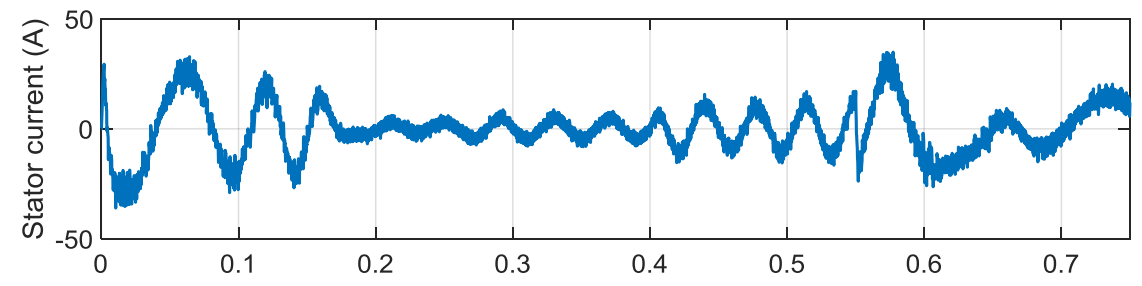

(a) Conventional method

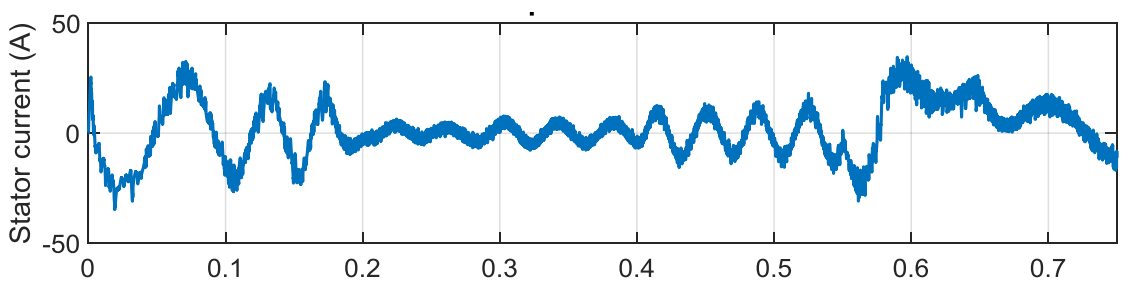

(b) Proposed method

Fig. 8 The stator current for the conventional method and proposed methods

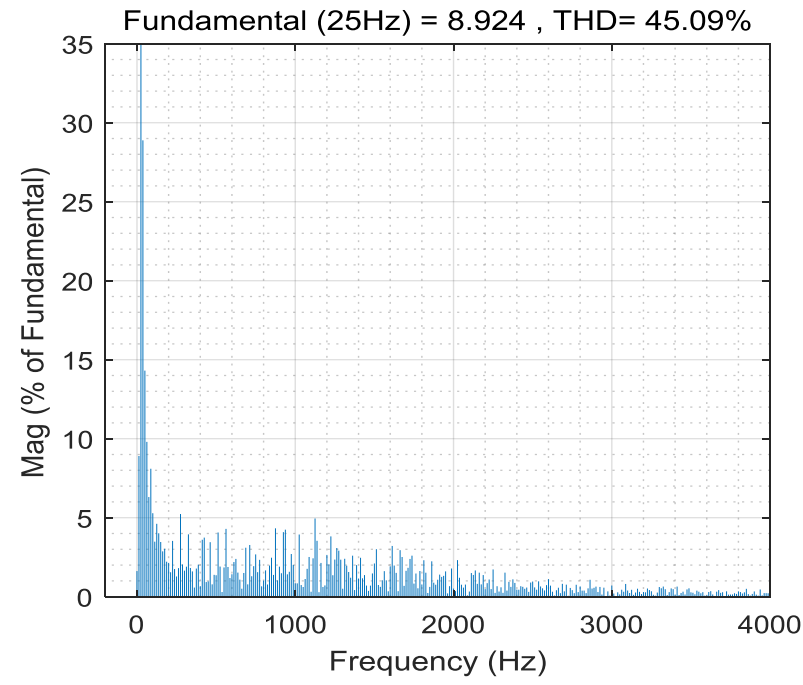

(a) Conventional method

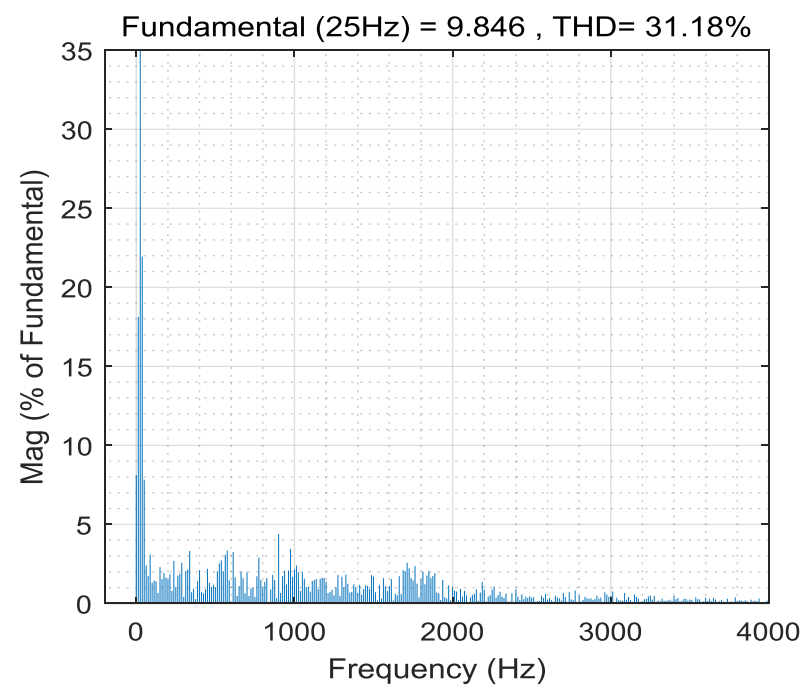

(b) Proposed method

Fig. 9 The harmonic spectrum of stator current for the conventional and proposed methods 
Figs. 8 and 9 illustrate the motor current and the harmonic spectrum of the stator current for both methods, respectively. The stator current THDs of the conventional and proposed methods are $45.09 \%$ and $31.18 \%$, individually. Consequently, in comparison to the conventional method, by increasing the switching frequency in the proposed method, the stator current THD relatively decreased up to $13.91 \%$.

In Fig.10, the steady-state torque characteristics after loading are shown in a zoom for both methods. The standard deviations of the proposed and conventional torque values are 5.1273 and 5.6703, respectively. Hence, it is compared to the conventional method, reducing the THD of the motor current by the proposed method decreasing the torque ripple up to $9.58 \%$.

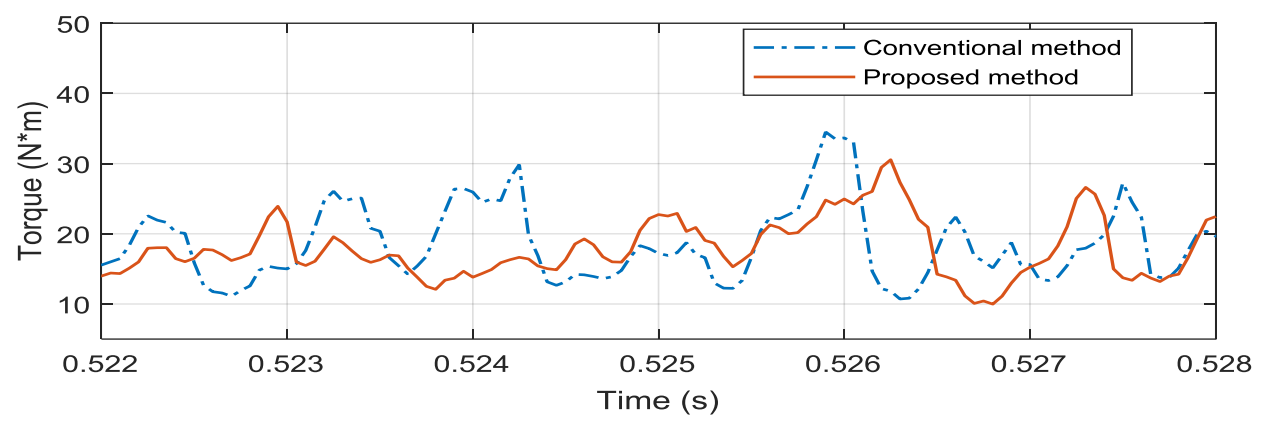

Fig. 10 The torque of the motor for the conventional and proposed methods in zoom

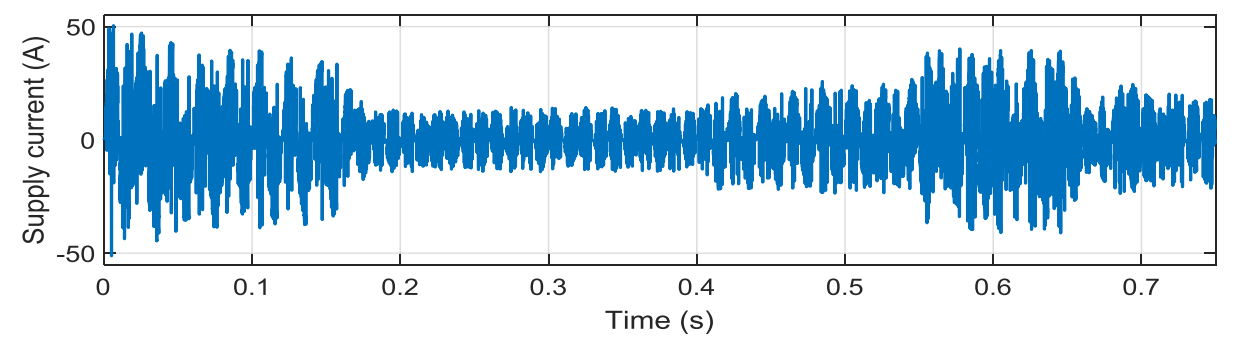

(a) Conventional method

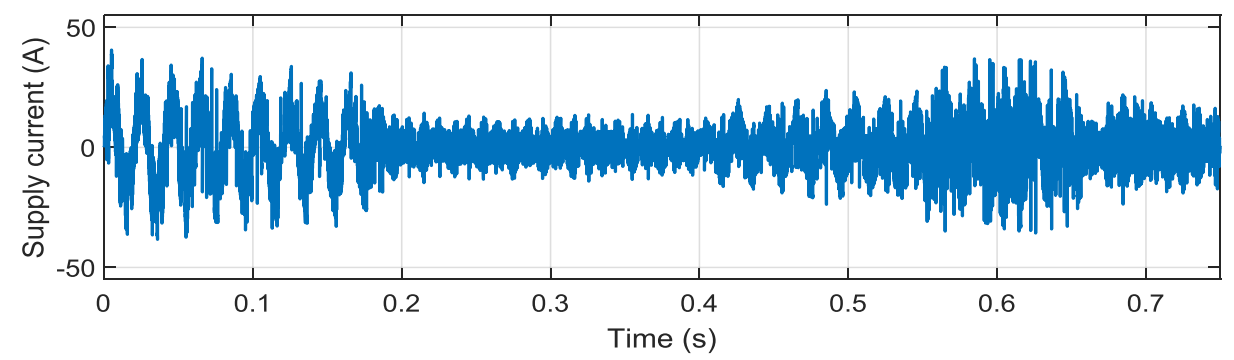

(b) Proposed method

Fig. 11 The supply current for the conventional method and proposed methods

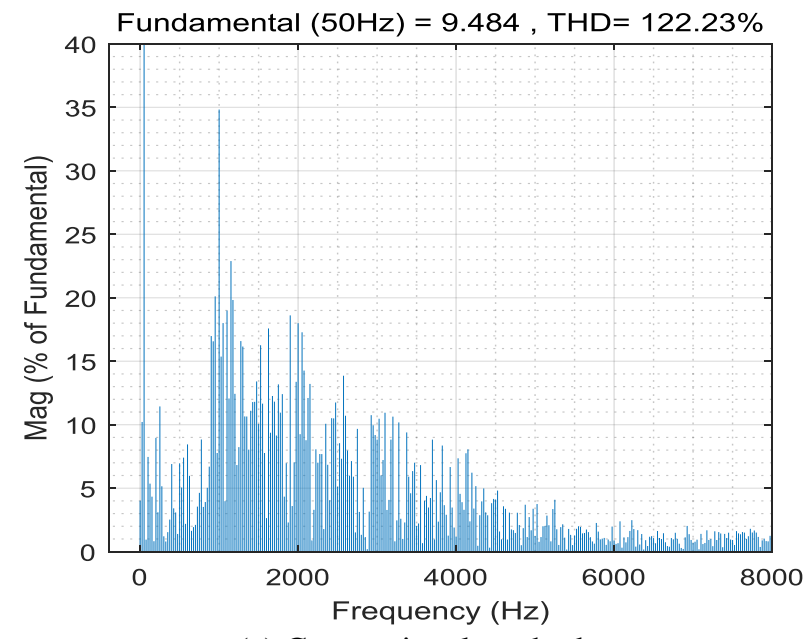

(a) Conventional method

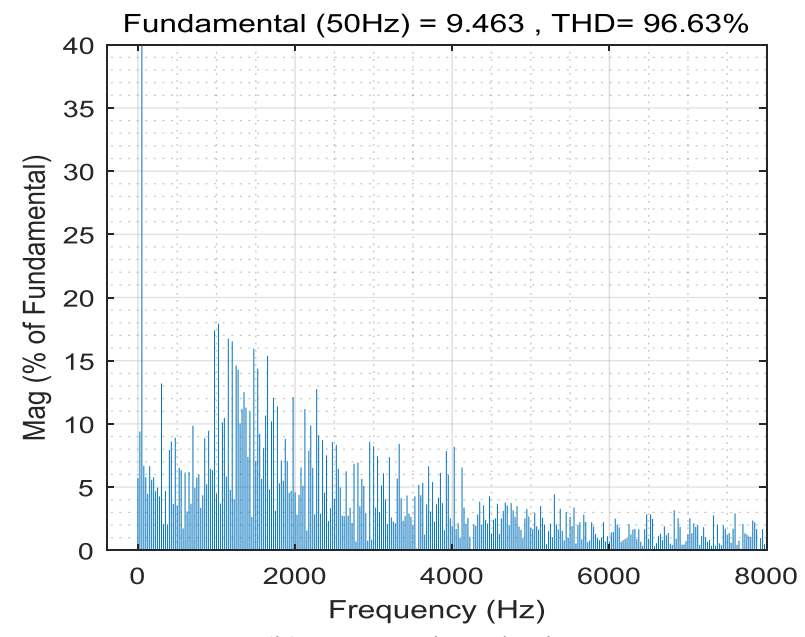

(b) Proposed method

Fig. 12 The harmonic spectrum of supply current for the conventional and proposed methods 
The waveform of the supply current for both conventional and proposed methods are shown in Fig. 11. The harmonic spectrum of the supply current whose the load torque is applied is drawn in Fig. 12 for both methods. As can be seen, the amplitude of the supply current harmonics is greater at frequencies less than $4 \mathrm{kHz}$ for the conventional method. However, there is an inverse relationship for frequencies above $4 \mathrm{kHz}$. The supply current THDs of the conventional and proposed methods are $122.23 \%$ and $96.63 \%$, respectively. Consequently, by increasing the switching frequency in the proposed method, the supply current THD considerably decreased up to $25.6 \%$ compared to the conventional method.

To analyze the switching power losses of the converter under the conventional and proposed methods, the SemiSel software which is designed by Semikron Corporation is recommended. The software suggests the IGBT package with the part number of SKM1200MLI12TE4 to estimate the switching power losses of the converter. In order to have a better comparison between two methods that work with different average switching frequencies, the loss effect can only be calculated for the diode-clamped inverter. Hence, the result of the comparison would be considered for the TLDCIMC with a rational approximation.

Considering the results in Table 2, the proposed method would lead to a 15 Watt more power loss in comparison to the conventional method. So, it revealed that increasing the switching frequency would not have a significant influence on the efficiency and the power loss of the inverter. Moreover, such an increase in the switching power losses against the high switching frequency of the proposed method which results in the remarkable reduction of the motor torque ripple. In addition, the source current THD seems to be acceptable and will be a good indication of the efficiency. Also, the superiority of the proposed control method in high-power drives.

Table 2 Results of the power loss calculation for the diode-clamped inverter by SemiSel

\begin{tabular}{|c|c|c|}
\hline Power losses & Proposed method & Conventional method \\
\hline Switching losses & $8.28 \mathrm{~W}$ & $14.58 \mathrm{~W}$ \\
\hline Conduction losses & $32.72 \mathrm{~W}$ & $41.42 \mathrm{~W}$ \\
\hline Total losses & $41 \mathrm{~W}$ & $56 \mathrm{~W}$ \\
\hline Efficiency & $98.7 \%$ & $98.2 \%$ \\
\hline
\end{tabular}

\section{Conclusion}

This research investigates the driving of an induction motor fed by a three-level diode-clamped indirect matrix converter using an improved FCS-MPC method. To do so, a cost function is defined with the main constraint of controlling the stator current. Reducing the motor torque ripple and the source current THD as two important factors in high-power drives are also considered in the proposed method. Thus, increasing the switching frequency is added to the cost function as another constraint which leads to achieving the aforementioned objectives. Despite the conventional methods, in this research, the switching frequency is increased by raising the number of commutations, and thus, there is no change in the sampling time. As a result, the microprocessor does not face numerous computational processes in a short cycle. This type of arrangement is extremely practical in high-power applications where having the least THD and ripple is highly desired.

Extensive simulation results using a co-simulation method based on finite element analysis and MATLAB/Simulink demonstrate that the proposed drive system properly follows the speed reference as well as the motor load torque with an appropriate dynamic response. Additionally, decreasing the motor current ripple results in reducing the THD of the input current. It is also observed that increasing the switching frequency in the proposed method would not have a significant effect on the efficiency and the power loss of the inverter compared to the conventional methods. This topology has a big opportunity for future research; one of the main areas which could be more improved is reducing the THD in such design which leads the topology to have fewer losses and more efficiency. 


\section{Conflicts of Interest}

The authors declare no conflict of interest.

\section{References}

[1] P. W. Wheeler, J. Rodriguez, J. C. Clare, L. Empringham, and A. Weinstein, "Matrix converters: a technology review," IEEE Transactions on Industrial Electronics, vol. 49, no. 2, pp. 276-288, April 2002.

[2] M. Diaz, R. Cardenas, M. Espinoza, C. M. Hackl, F. Rojas, J. C. Clare, et al., "Vector control of a modular multilevel matrix converter operating over the full output-frequency range," IEEE Transactions on Industrial Electronics, vol. 66, no. 7, pp. 5102-5114, July 2019.

[3] M. S. Mubarok and T. Liu, "Implementation of predictive controllers for matrix-converter-based interior permanent magnet synchronous motor position control systems," IEEE Journal of Emerging and Selected Topics in Power Electronics, vol. 7, no. 1, pp. 261-273, March 2019.

[4] J. Monteiro, J. F. Silva, S. F. Pinto, and J. Palma, "Linear and sliding-mode control design for matrix converter-based unified power flow controllers," IEEE Transactions on Power Electronics, vol. 29, no. 7, pp. 3357-3367, July 2014.

[5] G. F. Gontijo, T. C. Tricarico, B. W. França, L. F. Da Silva, E. L. Van Emmerik, and M. Aredes, "Robust model predictive rotor current control of a DFIG connected to a distorted and unbalanced grid driven by a direct matrix converter," IEEE Transactions on Sustainable Energy, vol. 10, no. 3, pp. 1380-1392, July 2019.

[6] A. Farhadi, A. Zakerian, and A. Nazari, "Predictive control of neutral-point clamped indirect matrix converter," Iranian Conference on Electrical Engineering (ICEE), IEEE Press, May 2017, pp. 1406-1411.

[7] J. Zhang, L. Li, D. G. Dorrell, M. Norambuena, and J. Rodriguez, "Predictive voltage control of direct matrix converters with improved output voltage for renewable distributed generation," IEEE Journal of Emerging and Selected Topics in Power Electronics, vol. 7, no. 1, pp. 296-308, March 2019.

[8] A. Zakerian and D. Nazarpour, "New hybrid structure based on improved switched inductor z-source and parallel inverters for renewable energy systems," International Journal of Power Electronics and Drive Systems (IJPEDS), vol. 6, no. 3, pp. 636-647, September 2015.

[9] Q. Jianglei, X. Lie, W. Lina, and H. Yannian, "Research on the modulation and control of multilevel matrix converter," The Journal of Engineering, vol. 2018, no. 13, pp. 614-621, August 2018.

[10] R. Wang, Z. Zhong, J. Zhang, and W. Wang, "Carrier-based PWM control strategy for three-level indirect matrix converter,” IET Power Electronics, vol. 12, no. 8, pp. 1964-1972, July 2019.

[11] Y. Sun, W. Xiong, M. Su, X. Li, H. Dan, and J. Yang, "Topology and modulation for a new multilevel diode-clamped matrix converter," IEEE Transactions on Power Electronics, vol. 29, no. 12, pp. 6352-6360, December 2014.

[12] Z. Chen, J. Qiu and M. Jin, "Prediction-error-driven position estimation method for finite-control-set model predictive control of interior permanent-magnet synchronous motors," IEEE Journal of Emerging and Selected Topics in Power Electronics, vol. 7, no. 1, pp. 282-295, March 2019.

[13] H. T. Nguyen and J. Jung, "Finite control set model predictive control to guarantee stability and robustness for surface-mounted pm synchronous motors,” IEEE Transactions on Industrial Electronics, vol. 65, no. 11, pp. 8510-8519, November 2018.

[14] X. Zhang, G. Tan, T. Xia, Q. Wang, and X. Wu, "Optimized switching finite control set model predictive control of NPC single-phase three-level rectifiers," IEEE Transactions on Power Electronics, vol. 35, no. 10, pp. 10097-10108, October 2020.

[15] M. M. Aghdam, L. Li, and J. Zhu, "Comprehensive study of finite control set model predictive control algorithms for power converter control in microgrids," IET Smart Grid, vol. 3, no. 1, pp. 1-10, March 2020.

[16] H. A. Young, V. A. Marin, C. Pesce, and J. Rodriguez, "Simple finite-control-set model predictive control of grid-forming inverters with LCL filters," IEEE Access, vol. 8, pp. 81246-81256, April 2020.

[17] M. Rivera, "Predictive control with imposed sinusoidal source and load currents of an indirect matrix converter operating at fixed switching frequency,” 2015 IEEE 24th International Symposium on Industrial Electronics (ISIE), Buzios, October 2015, pp. 391-397.

[18] P. Cortes, M. P. Kazmierkowski, R. M. Kennel, D. E. Quevedo, and J. Rodriguez, "Predictive control in power electronics and drives," IEEE Transactions on Industrial Electronics, vol. 55, no. 12, pp. 4312-4324, December 2008.

[19] M. Khosravi, M. Amirbande, D. A. Khaburi, M. Rivera, J. Riveros, J. Rodriguez, et al., "Review of model predictive control strategies for matrix converters,” IET Power Electronics, vol. 12, no. 12, pp. 3021-3032, October 2019. 
[20] R. N. Beres, X. Wang, M. Liserre, F. Blaabjerg, and C. L. Bak, "A review of passive power filters for three-phase grid-connected voltage-source converters," IEEE Journal of Emerging and Selected Topics in Power Electronics, vol. 4, no. 1, pp. 54-69, March 2016.

[21] C. L. Toh, N. N. Idris, and A. H. M. Yatim, "Constant and high switching frequency torque controller for DTC drives," IEEE Power Electronics Letters, vol. 3, no. 2, pp. 76-80, June 2005.

[22] J. Rodriguez, M. Rivera, J. W. Kolar, and P. W. Wheeler, "A review of control and modulation methods for matrix converters," IEEE Transactions on Industrial Electronics, vol. 59, no. 1, pp. 58-70, January 2012.

[23] M. Rivera, P. Wheeler, J. Rodriguez, and B. Wu, "A review of predictive control techniques for matrix converter applications," IECON 2017 - 43rd Annual Conference of the IEEE Industrial Electronics Society, IEEE Press, October 2017, pp. 7360-7365.

[24] A. Edpuganti and A. K. Rathore, "Fundamental Switching frequency optimal pulse width modulation of medium-voltage cascaded seven-level inverter," IEEE Transactions on Industry Applications, vol. 51, no. 4, pp. 3485-3492, July-August 2015.

[25] R. M. Tallam, R. Naik, and T. A. Nondahl, "A carrier-based PWM scheme for neutral-point voltage balancing in three-level inverters," IEEE Transactions on Industry Applications, vol. 41, no. 6, pp. 1734-1743, November-December 2005.

[26] M. Rivera, C. Rojas, A. Wilson, J. Rodriguez, J. Espinoza, C. Baier et al., "Review of predictive control methods to improve the input current of an indirect matrix converter," IET Power Electronics, vol. 7, no. 4, pp. 886-894, April 2014.

[27] A. Dötlinger and R. M. Kennel, "Near time-optimal model predictive control using an L1-norm based cost functional," 2014 IEEE Energy Conversion Congress and Exposition (ECCE), September 2014, pp. 3504-3511.

[28] L. Yan, M. Dou, Z. Hua, H. Zhang, and J. Yang, "Robustness improvement of FCS-MPTC for induction machine drives using disturbance feedforward compensation technique," IEEE Transactions on Power Electronics, vol. 34, no. 3, pp. 2874-2886, March 2019.

[29] User's guide: software component of cedrat flux 2D, Vers. 11.2, Cedrat FLUX, 2013, http://www.tianyuantech.com/download/flux112.pdf.

Copyright $(\odot$ by the authors. Licensee TAETI, Taiwan. This article is an open access article distributed under the terms and conditions of the Creative Commons Attribution (CC BY-NC) license (https://creativecommons.org/licenses/by-nc/4.0/).

\section{Appendix}

The correct switching states of the TLDCIMC are as follows:

Table A.1 Upper rectifier switching states

\begin{tabular}{|c|c|c|c|c|c|c|c|c|c|c|}
\hline No. & $\mathrm{S}_{\mathrm{rp} 1}$ & $\mathrm{~S}_{\mathrm{rp} 2}$ & $\mathrm{~S}_{\mathrm{rp} 3}$ & $\mathrm{~S}_{\mathrm{rp} 4}$ & $\mathrm{~S}_{\mathrm{rp} 5}$ & $\mathrm{~S}_{\mathrm{rp} 6}$ & $\mathrm{i}_{\mathrm{A} 1}$ & $\mathrm{i}_{\mathrm{B} 1}$ & $\mathrm{i}_{\mathrm{C} 1}$ & $\mathrm{~V}_{\mathrm{p}}$ \\
\hline 1 & 1 & 1 & 0 & 0 & 0 & 0 & $\mathrm{I}_{\mathrm{p}}$ & 0 & $\mathrm{I}_{\mathrm{z}} / 2$ & $\mathrm{v}_{\mathrm{AC} 1}$ \\
\hline 2 & 0 & 1 & 1 & 0 & 0 & 0 & 0 & $\mathrm{I}_{\mathrm{p}}$ & $\mathrm{I}_{\mathrm{z}} / 2$ & $\mathrm{v}_{\mathrm{BC} 1}$ \\
\hline 3 & 0 & 0 & 1 & 1 & 0 & 0 & $\mathrm{I}_{\mathrm{z}} / 2$ & $\mathrm{I}_{\mathrm{p}}$ & 0 & $-\mathrm{v}_{\mathrm{AB} 1}$ \\
\hline 4 & 0 & 0 & 0 & 1 & 1 & 0 & $\mathrm{I}_{\mathrm{z}} / 2$ & 0 & $\mathrm{I}_{\mathrm{p}}$ & $-\mathrm{v}_{\mathrm{AC} 1}$ \\
\hline 5 & 0 & 0 & 0 & 0 & 1 & 1 & 0 & $\mathrm{I}_{\mathrm{z}} / 2$ & $\mathrm{I}_{\mathrm{p}}$ & $-\mathrm{v}_{\mathrm{BC} 1}$ \\
\hline 6 & 1 & 0 & 0 & 0 & 0 & 1 & $\mathrm{I}_{\mathrm{p}}$ & $\mathrm{I}_{\mathrm{z}} / 2$ & 0 & $\mathrm{v}_{\mathrm{AB} 1}$ \\
\hline
\end{tabular}

Table A.2 Lower rectifier switching states

\begin{tabular}{|c|c|c|c|c|c|c|c|c|c|c|}
\hline No. & $\mathrm{S}_{\mathrm{rp} 1}$ & $\mathrm{~S}_{\mathrm{rp} 2}$ & $\mathrm{~S}_{\mathrm{rp} 3}$ & $\mathrm{~S}_{\mathrm{rp} 4}$ & $\mathrm{~S}_{\mathrm{rp} 5}$ & $\mathrm{~S}_{\mathrm{rp} 6}$ & $\mathrm{i}_{\mathrm{A} 1}$ & $\mathrm{i}_{\mathrm{B} 1}$ & $\mathrm{i}_{\mathrm{C} 1}$ & $\mathrm{~V}_{\mathrm{p}}$ \\
\hline 1 & 1 & 1 & 0 & 0 & 0 & 0 & $-\mathrm{I}_{\mathrm{z}} / 2$ & 0 & $-\mathrm{I}_{\mathrm{n}}$ & $\mathrm{v}_{\mathrm{AC} 2}$ \\
\hline 2 & 0 & 1 & 1 & 0 & 0 & 0 & 0 & $-\mathrm{I}_{\mathrm{z}} / 2$ & $-\mathrm{I}_{\mathrm{n}}$ & $\mathrm{v}_{\mathrm{BC} 2}$ \\
\hline 3 & 0 & 0 & 1 & 1 & 0 & 0 & $-\mathrm{I}_{\mathrm{n}}$ & $-\mathrm{I}_{\mathrm{z}} / 2$ & 0 & $-\mathrm{v}_{\mathrm{AB} 2}$ \\
\hline 4 & 0 & 0 & 0 & 1 & 1 & 0 & $-\mathrm{I}_{\mathrm{n}}$ & 0 & $-\mathrm{I}_{\mathrm{z}} / 2$ & $-\mathrm{v}_{\mathrm{AC} 2}$ \\
\hline 5 & 0 & 0 & 0 & 0 & 1 & 1 & 0 & $-\mathrm{I}_{\mathrm{n}}$ & $-\mathrm{I}_{\mathrm{z}} / 2$ & $-\mathrm{v}_{\mathrm{BC} 2}$ \\
\hline 6 & 1 & 0 & 0 & 0 & 0 & 1 & $-\mathrm{I}_{\mathrm{z}} / 2$ & $-\mathrm{I}_{\mathrm{n}}$ & 0 & $\mathrm{v}_{\mathrm{AB} 2}$ \\
\hline
\end{tabular}


Table A.3 Switching states of the diode-clamped inverter

\begin{tabular}{|c|c|c|c|c|c|c|c|c|c|c|c|}
\hline No. & $\mathrm{S}_{\mathrm{a} 1}$ & $\mathrm{~S}_{\mathrm{b} 1}$ & $\mathrm{~S}_{\mathrm{a} 3}$ & $\mathrm{~S}_{\mathrm{b} 3}$ & $\mathrm{~S}_{\mathrm{a} 5}$ & $\mathrm{~S}_{b 5}$ & $\mathrm{v}_{\mathrm{ab}}$ & $\mathrm{v}_{\mathrm{bc}}$ & $\mathrm{v}_{\mathrm{ca}}$ & $\mathrm{I}_{\mathrm{p}}$ & $\mathrm{I}_{\mathrm{n}}$ \\
\hline 1 & 0 & 0 & 0 & 0 & 0 & 0 & 0 & 0 & 0 & 0 & 0 \\
\hline 2 & 0 & 0 & 0 & 0 & 0 & 1 & 0 & 0 & $V_{n}$ & 0 & $-i_{a}-i_{b}$ \\
\hline 3 & 0 & 0 & 0 & 0 & 1 & 1 & 0 & $-V_{n}-V_{p}$ & $V_{n}+V_{p}$ & $i_{c}$ & $-i_{a}-i_{b}$ \\
\hline 4 & 0 & 0 & 0 & 1 & 0 & 0 & $-V_{n}$ & $V_{n}$ & 0 & 0 & $-i_{a}-i_{c}$ \\
\hline 5 & 0 & 0 & 0 & 1 & 0 & 1 & $-V_{n}$ & 0 & $V_{n}$ & 0 & $-i_{a}$ \\
\hline 6 & 0 & 0 & 0 & 1 & 1 & 1 & $-V_{n}$ & $-V_{p}$ & $V_{n}+V_{p}$ & $i_{c}$ & $-i_{b}-i_{c}$ \\
\hline 7 & 0 & 0 & 1 & 1 & 0 & 0 & $-V_{n}-V_{p}$ & $V_{n}+V_{p}$ & 0 & $i_{b}$ & $-i_{a}-i_{c}$ \\
\hline 8 & 0 & 0 & 1 & 1 & 0 & 1 & $-V_{n}-V_{p}$ & $V_{p}$ & $V_{n}$ & $i_{b}$ & $-i_{b}-i_{c}$ \\
\hline 9 & 0 & 0 & 1 & 1 & 1 & 1 & $-V_{n}-V_{p}$ & 0 & $V_{n}+V_{p}$ & $i_{b}+i_{c}$ & $-i_{a}$ \\
\hline 10 & 0 & 1 & 0 & 0 & 0 & 0 & $V_{n}$ & 0 & $-V_{n}$ & 0 & $-i_{b}-i_{c}$ \\
\hline 11 & 0 & 1 & 0 & 0 & 0 & 1 & $V_{n}$ & $-V_{n}$ & 0 & 0 & $-i_{b}$ \\
\hline 12 & 0 & 1 & 0 & 0 & 1 & 1 & $V_{n}$ & $-V_{n}-V_{p}$ & $V_{p}$ & $i_{c}$ & $-i_{b}$ \\
\hline 13 & 0 & 1 & 0 & 1 & 0 & 0 & 0 & $V_{n}$ & $-V_{n}$ & 0 & $-i_{c}$ \\
\hline 14 & 0 & 1 & 0 & 1 & 0 & 1 & 0 & 0 & 0 & 0 & 0 \\
\hline 15 & 0 & 1 & 0 & 1 & 1 & 1 & 0 & $-V_{p}$ & $V_{p}$ & $i_{c}$ & 0 \\
\hline 16 & 0 & 1 & 1 & 1 & 0 & 0 & $-V_{p}$ & $V_{n}+V_{p}$ & $-V_{n}$ & $i_{b}$ & $-i_{c}$ \\
\hline 17 & 0 & 1 & 1 & 1 & 0 & 1 & $-V_{p}$ & $V_{p}$ & 0 & $i_{b}$ & 0 \\
\hline 18 & 0 & 1 & 1 & 1 & 1 & 1 & $-V_{p}$ & 0 & $V_{p}$ & $i_{b}+i_{c}$ & 0 \\
\hline 19 & 1 & 1 & 0 & 0 & 0 & 0 & $V_{n}+V_{p}$ & 0 & $-V_{n}-V_{p}$ & $i_{a}$ & $-i_{b}-i_{c}$ \\
\hline 20 & 1 & 1 & 0 & 0 & 0 & 1 & $V_{n}+V_{p}$ & $-V_{n}$ & $-V_{p}$ & $i_{a}$ & $-i_{b}$ \\
\hline 21 & 1 & 1 & 0 & 0 & 1 & 1 & $V_{n}+V_{p}$ & $-V_{n}-V_{p}$ & 0 & $i_{a}+i_{c}$ & $-i_{b}$ \\
\hline
\end{tabular}

Table A.3 Switching states of the diode-clamped inverter (continued)

\begin{tabular}{|c|c|c|c|c|c|c|c|c|c|c|c|}
\hline No. & $\mathrm{S}_{\mathrm{a} 1}$ & $\mathrm{~S}_{\mathrm{b} 1}$ & $\mathrm{~S}_{\mathrm{a} 3}$ & $\mathrm{~S}_{\mathrm{b} 3}$ & $\mathrm{~S}_{\mathrm{a} 5}$ & $\mathrm{~S}_{b 5}$ & $\mathrm{v}_{\mathrm{ab}}$ & $\mathrm{v}_{\mathrm{bc}}$ & $\mathrm{v}_{\mathrm{ca}}$ & $\mathrm{I}_{\mathrm{p}}$ & $\mathrm{I}_{\mathrm{n}}$ \\
\hline 22 & 1 & 1 & 0 & 1 & 0 & 0 & $V_{p}$ & $V_{n}$ & $-V_{n}-V_{p}$ & $i_{a}$ & $-i_{c}$ \\
\hline 23 & 1 & 1 & 0 & 1 & 0 & 1 & $V_{p}$ & 0 & $-V_{p}$ & $i_{a}$ & 0 \\
\hline 24 & 1 & 1 & 0 & 1 & 1 & 1 & $V_{p}$ & $-V_{p}$ & 0 & $i_{a}+i_{c}$ & 0 \\
\hline 25 & 1 & 1 & 1 & 1 & 0 & 0 & 0 & $V_{n}+V_{p}$ & $-V_{n}-V_{p}$ & $i_{a}+i_{b}$ & $-i_{c}$ \\
\hline 26 & 1 & 1 & 1 & 1 & 0 & 1 & 0 & $V_{p}$ & $-V_{p}$ & $i_{a}+i_{b}$ & 0 \\
\hline 27 & 1 & 1 & 1 & 1 & 1 & 1 & 0 & 0 & 0 & 0 & 0 \\
\hline
\end{tabular}

